\title{
Walking behaviour and spatial use of broiler chickens
}

\author{
Arda Aydin \\ Department of Agricultural Machineries and Technologies Engineering, Faculty of Agriculture, \\ Canakkale Onsekiz Mart University, 17020 Canakkale, Turkey \\ e-mail: araydin@comu.edu.tr
}

Keywords: Broiler chicken, activity, spatial use, housing

\begin{abstract}
Modern broiler chickens are genetically selected for reaching higher weights in shorter life spans. In addition to this, they are raised in crowded housing conditions with less opportunity for movement. Understanding movement patterns, migration and use of space is essential in determining welfare of the birds in commercial farms. In this study, migration behaviour of broiler chickens in semi-commercial farms of 1800 chickens was studied. Observations were repeated in six growth periods each on 12 chickens once a day during their growth period of 42 days. It was seen that the activity of broilers was not decreasing during the growth period. Travelled distances of the chickens in total were not reduced in the last 3 weeks of their growth period ( $p>0.05$ in $89 \%$ of the observed birds, Mann-Whitney U test). Chickens preferred to be in the zones next to the wall farthest to the entrance of the house. The observed birds did not restrict themselves only around the feeders and the drinkers but used the whole surface area available during the whole growth period. The results of the study seem to be encouraging in achieving welfare of broiler chickens even in commercialised houses with high stocking density. Reported mobility of chickens is important for their survival and has therefore considerable impact on efficient production on farms.
\end{abstract}

\section{INTRODUCTION}

Modern broiler chicken has been genetically selected for maximising production results. Birds can reach weights around $2.5 \mathrm{~kg}$ in periods of only 6 weeks. Heavier body weights, uneven distribution of weight within the body and incompetent muscle growth cause less movement or locomotion disorders in the animals [8]. In addition to this, in commercial farms chickens are raised typically in large enclosures as big flocks of 10.000 animals and more. Birds live therefore in dense populations in constrained spaces reaching high stocking densities [16]. Management practices such as dimmed lighting conditions also discourage the amount of movement. The influence of lighting conditions on chickens' activity has been studied by [9].

In the case of broiler chickens, abnormal walking is a key indicator of reduced welfare [20, 21 , 22]. Understanding the space use in captive birds is essential in promoting welfare by optimizing the space quality and fulfilling the animals' biological needs. It was showed [10] that the size and density are the main factors for the movement and space use of domestic chicken. It was found out [12] that exploratory motivation of chickens declines after about 4 to 5 weeks of age possible due to the increased energetic cost and the increasing familiarity with the area. Broiler breeders in commercial flocks of nearly 4000 birds by tagging individuals were studied [1]. It was shown that the birds in commercial flocks do not restrict their movement to small areas and that there were no consistent changes in the area used with time. Higher use of wall regions has also been detected for commercial flock of broilers by [14].

Results of [2] showed that broilers at the higher density (15 chickens $/ \mathrm{m}^{2}$ ) generally stayed and sit down in the free areas without feeders and the drinkers. At the lower density $\left(2\right.$ chickens $\left./ \mathrm{m}^{2}\right)$ the birds choose to sit down close to drinkers and feeders. These results indicated that the broilers automatically stinted their physical effort and occasionally went to some parts of the pen [2]. They also concluded that the broilers raised at the high density collected near the walls, despite this behaviour disappeared at the end of the raised period when the floor space covered by the body surface of the broilers [2]. 
Behaviour of 12 marked birds in a commercial broiler farm was studied by [14] from day 27 to day 42. It was shown that birds continuously moved around the house during the growth period and the lowest average daily movement was $3.4 \mathrm{~m}$. Their conclusion that the individual broilers were not limited in movement to areas occupied by known broilers is coherent with the results of [1]. However, it was not in agreement with the findings of [11] for laying hens, and with [15] who suggested an evident drop in walking distance in week 3 in the animals. It was concluded [7] that, the birds try to spend their time by resting on the litter floor. A similar behaviour was detected by $[5,6]$. A prominent decrease in movement activity was reported by [3] at the end of the growing period while sitting or resting time rises. The resting time cover about 80 to $90 \%$ of the total time. The same results were also defined by [13]. In a recent research, walking behaviour of heavy and light broilers was investigated by [17]. They concluded that the latter effect was stronger in the low body weight group than in the high body weight group indicating a better physical ability. Furthermore, their experiment showed that distance walked was affected both by physical ability and motivation [17]. In another very recent research, the use of morphological asymmetry data to estimate broiler walking ability and welfare was investigated by [18]. It was concluded that the welfare of broilers with walking difficulty due to the presence of severe asymmetry in limbs is poor [18]. In another research in 2013, the effect of different LED light colour on the behaviour and fear responses of broilers was investigated by [19]. They concluded that red and red-yellow light activated the broiler's movement and fear responses while blue and green-blue decreased the movement and they spent more time sitting [19]. Studies in general suggest that although during the growth period, activity of the chickens decrease, the distance travelled during the day does not decrease which may be explained by the exploratory behaviour of the animals.

The purpose of this paper is to analyse the migration behaviour and spatial use of marked broiler chickens in semi-commercial farms of 1800 chickens during their growth period of 42 days. This study focuses on whether individual birds restricted themselves in certain areas, if the movement decreases with age and if there are specific trajectories or preferred locations inside the house. In contrast to the study of [14] who have observed broiler chickens only from day 26 to slaughter age of 42 days, this paper investigates the migration behaviour during a full growth period of 42 days. In addition to that, this study aimed at testing whether the conclusions of [14] for no particular home range were similar not only for 16 days but for the whole growth period of 42 days.

\section{MATERIALS AND METHODS}

\section{Experimental setup}

The experiments were conducted in the Provincial Centre for Applied Poultry Research, Province Antwerp ( Belgium) between November 2012 and April 2014. The experiments were performed with 1800 broilers (Ross 308) during a raising period of 42 days in a broiler house dimensions with $16 \times 12 \mathrm{~m}$. The birds were kept on straw. The stocking density was 15 broilers per $\mathrm{m}^{2}$. The animals were cured against infectious bronchitis $\left(\mathrm{NOBILIS}^{\circledR}\right.$,IB H120, Intervet International, Boxmeer, The Netherlands) and Newcastle Disease with a vaccination (NOBILIS ${ }^{\circledR}$, ND CLONE 30, Intervet International, Boxmeer, The Netherlands).

The broiler house was accoutred with fans pulling the air in the house [Fig. 1]. The broiler house was heated by a central warming system with hot water pipes under the roof. It was also modified with an automatic feeding system (Minimax ${ }^{\circledR}$, Roxell n.v., Maldegem, Belgium) and four weighing scales with $0.38 \mathrm{~m}$ diameter and $0.1 \mathrm{~g}$ accuracy connected to a computer. Average air temperature was set to $21^{\circ} \mathrm{C}$ during the experiments. The lighting schedule was $23 \mathrm{~h}$ of light and $1 \mathrm{~h}$ of darkness. 


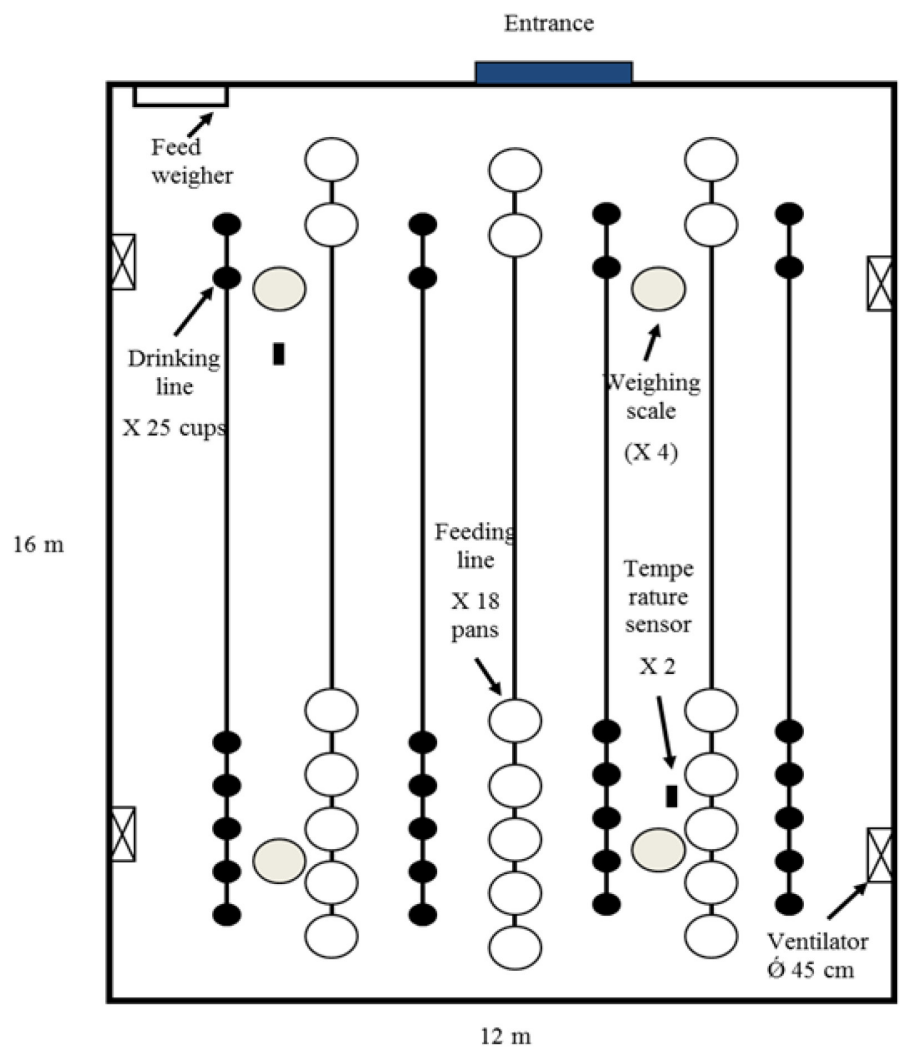

Fig. 1. A schematic top view of the experimental test installation.

\section{Diets}

Feed and water was ad libitum for the broilers during the experiments. A starter feed followed by a grower feed. A starter diet with $211 \mathrm{~g} / \mathrm{kg} \mathrm{CP}$ and $2960 \mathrm{kcal} \mathrm{AME} / \mathrm{kg}$ was served until 10 days of age and a grower diet with $209 \mathrm{~g} / \mathrm{kg} \mathrm{CP}$ and $3060 \mathrm{kcal} \mathrm{AME} / \mathrm{kg}$ was given from d $11 \mathrm{until} \mathrm{d} 42$.

\section{Measurements}

Twelve one-day-old chicks were randomly chosen and tagged with different colours to facilitate the visual tracking of the animal. The position of the animals in the stable was observed from day 1 to day 42 once a day at 10:00 h (in the morning) by a trained expert. This procedure was repeated during six 42-days growth periods, observations have been made on 72 broiler chickens (6 experiments $\mathrm{x} 12$ chickens).

\section{Data Analysis}

The surface area of the house was divided into 16 equal rectangles $(2 \times 1.5 \mathrm{~m})$. Distances travelled by individual animals were calculated on a centre to centre basis for consecutive observations ( 24 hours). Total number of animals located in a certain position was calculated for the whole growth period. Mann-Whitney U test was used for assessing whether average distances moved between first 3 weeks and last 3 weeks of growth were significantly different from each other. Statistics Toolbox of Matlab Software (The Mathworks, Massachusetts, USA) was used for the calculations. Furthermore, to test the hypothesis whether observed chickens preferred specific zones in the farming house we have divided the surface of the house into four zones [Fig. 2]. An independent t-test was used to determine significant difference in number of visits between the zone1, farthest from the wall and the rest of the zones. 


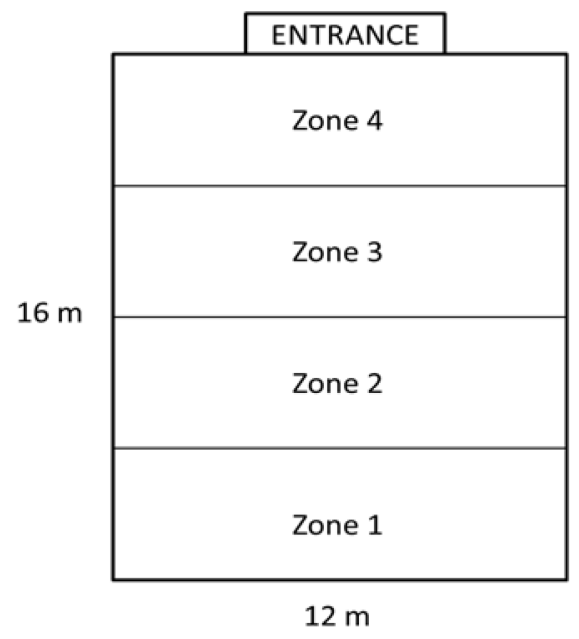

Fig. 2. The surface of the house divided into 4 larger zones to check the spatial preferences of observed broiler chickens.

\section{RESULTS}

In this study 12 individual birds in a broiler house of 1800 birds were visually monitored every day during their growth period of 6 weeks. This procedure was repeated six times in order to observe the activity levels and space use of individual chickens in a semi-commercial housing system.

The average daily movements of the birds, as defined higher, ranged between of 0 to 15 meters during 1 day in terms of centre to centre of each rectangular section $(2 \mathrm{~m} \mathrm{x} 1.5 \mathrm{~m})$. Thus, some of the observed chickens moved larger distances of $15 \mathrm{~m}$ during one day. Activity of the birds in terms of walking distances was examined and it was shown that it was at random basis during the growth period and did not depend on the age of the birds [Table 1]. As an example, we show the distance (m) travelled in consecutive 24-hour periods by three out of the twelve different chickens in all six experiment rounds [Fig. 3]. The individual graphs in figure 3 are missing some data points due to the fact that there were no observations during weekends. Chicken 1,2 and 3 in figure 3 were different birds per experiment.

It can be seen that the activity of the chickens strongly varied from day to day and did not show a significant decrease towards the end of the growth period. Table 1 shows results from a MannWhitney $U$ test for testing the hypothesis whether average distances moved during the first 3 weeks and last 3 weeks of growth were significantly different from each other. When analysing individual chickens and comparing their travelled distances between first and last 3 weeks of their growth period [Table 1] eight out of in total 72 chickens showed significant difference in moving. The rest of the observed chickens, which means $89 \%$ of the chickens' sample, did not demonstrate any significant difference in moving between the first and the last 3 weeks of their growth period. 


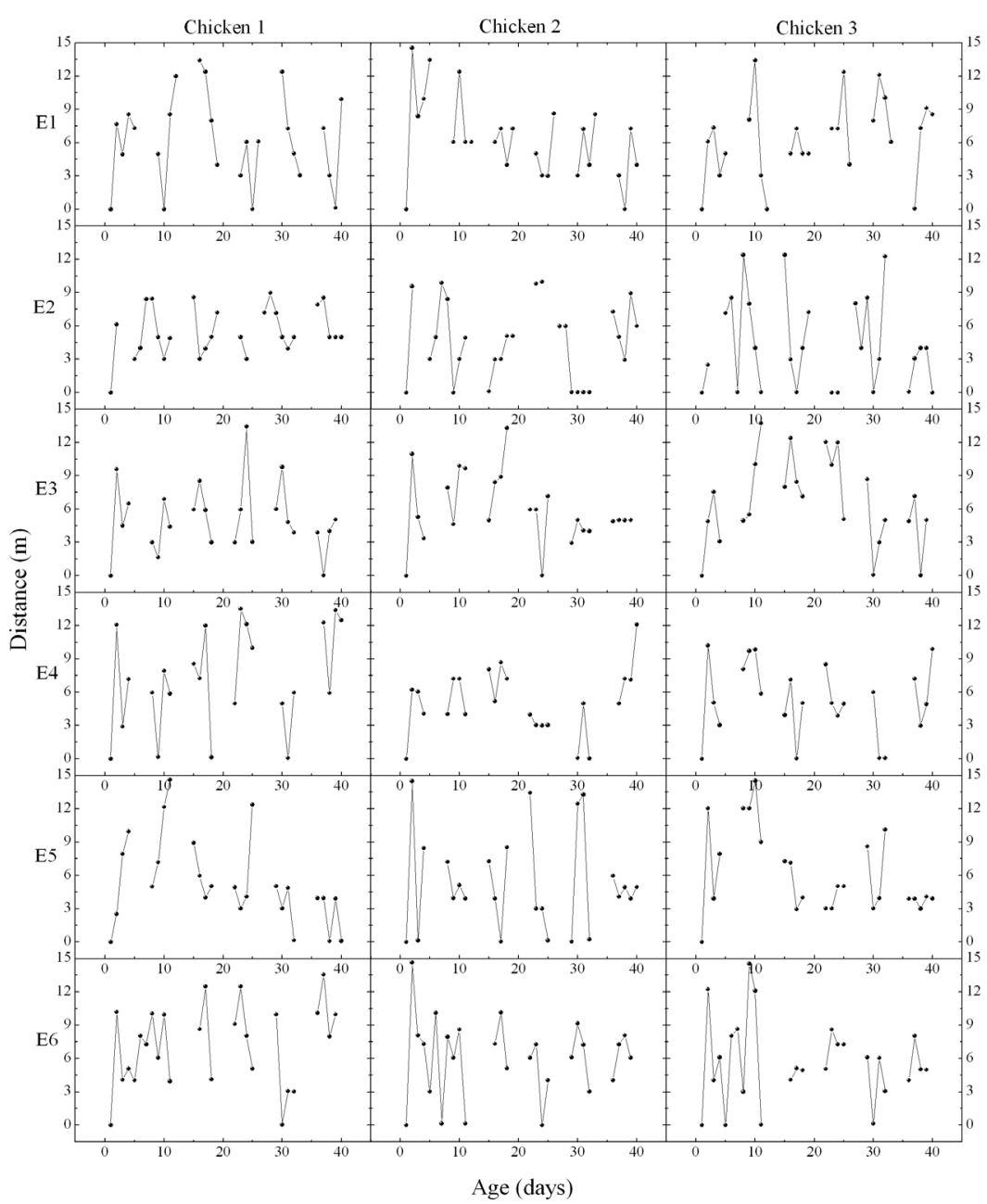

Fig. 3. The distance $(\mathrm{m})$ travelled in consecutive 24 hours by three different randomly selected chickens in all six experiments.

For every experiment, the total number of visits to each of the 16 rectangular parts was calculated. Observations for all 12 chickens for each experiment are summarized and shown in figure 4. In order to smoothen the changes in the plots of figure $4, n$ interpolation between rectangular zones was done. From these observations, it could be seen that chickens preferred the zones inside the house farthest from the entrance with less distraction.
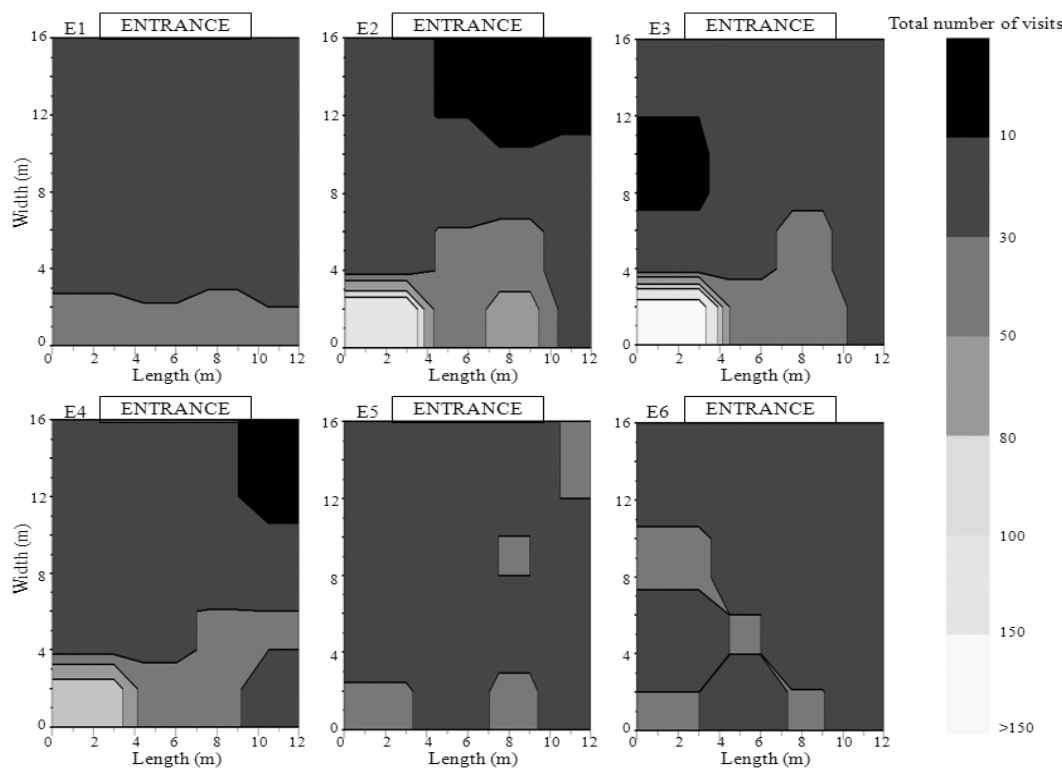

Fig. 4. Spatial distribution of chicken in all six experiments. The number of visits to each of the 16 rectangular sections was summarized for all 12 chickens during 42 days. 
Table 1. $P$ values obtained with Mann-Whitney $U$ test for testing the hypothesis whether average distances moved during the first 3 weeks and last 3 weeks of growth were significantly different from each other. The test was done for the 12 individual chickens in all six experiments. All six experiments were done with different chicken groups.

\begin{tabular}{|c|c|c|c|c|c|c|}
\hline & $\begin{array}{c}\text { Experiment } \\
1 \\
\mathrm{P} \text { value }\end{array}$ & $\begin{array}{c}\text { Experiment } \\
2 \\
\mathrm{P} \text { value } \\
\end{array}$ & $\begin{array}{c}\text { Experiment } \\
3 \\
\mathrm{P} \text { value } \\
\end{array}$ & $\begin{array}{c}\text { Experiment } \\
4 \\
\text { P value } \\
\end{array}$ & $\begin{array}{c}\text { Experiment } \\
5 \\
\mathrm{P} \text { value } \\
\end{array}$ & $\begin{array}{c}\text { Experiment } \\
6 \\
\mathrm{P} \text { value } \\
\end{array}$ \\
\hline Chicken 1 & 0.25 & 0.68 & 0.86 & 0.1 & $0.007 *$ & 0.82 \\
\hline Chicken 2 & 0.08 & 0.77 & 0.07 & 0.44 & 0.31 & 0.12 \\
\hline Chicken 3 & 0.33 & 0.4 & 0.18 & 0.96 & $0.04 *$ & 0.4 \\
\hline Chicken 4 & 0.15 & 0.22 & 0.38 & 0.4 & $0.03 *$ & 0.71 \\
\hline Chicken 5 & 0.52 & 0.078 & 0.37 & 0.84 & $0.03 *$ & 0.05 \\
\hline Chicken 6 & 0.42 & 0.79 & 0.98 & 0.59 & 0.84 & 0.62 \\
\hline Chicken 7 & 0.86 & 0.23 & 0.24 & 0.23 & 0.085 & 0.26 \\
\hline Chicken 8 & 0.09 & 0.2 & 0.28 & 0.59 & 0.36 & 1 \\
\hline Chicken 9 & $0.03 *$ & 0.41 & 0.61 & 0.44 & 0.25 & $0.03 *$ \\
\hline Chicken 10 & 0.78 & 0.42 & 0.98 & 0.59 & $0.0004 *$ & $0.004^{*}$ \\
\hline Chicken 11 & 0.89 & 0.64 & 0.13 & 0.08 & 0.67 & 0.16 \\
\hline Chicken 12 & 0.07 & 0.45 & 0.14 & 0.38 & 0.16 & 0.32 \\
\hline
\end{tabular}

* significant difference $(\mathrm{p}<0.05)$

To test the hypothesis that chicken preferred zones around the wall farthest from the entrance in a more quantitative way, we have divided the surface of the house into four zones [Fig. 2]. The average number of chickens' visits to each of the zone was calculated for every experiment [Fig. 5].

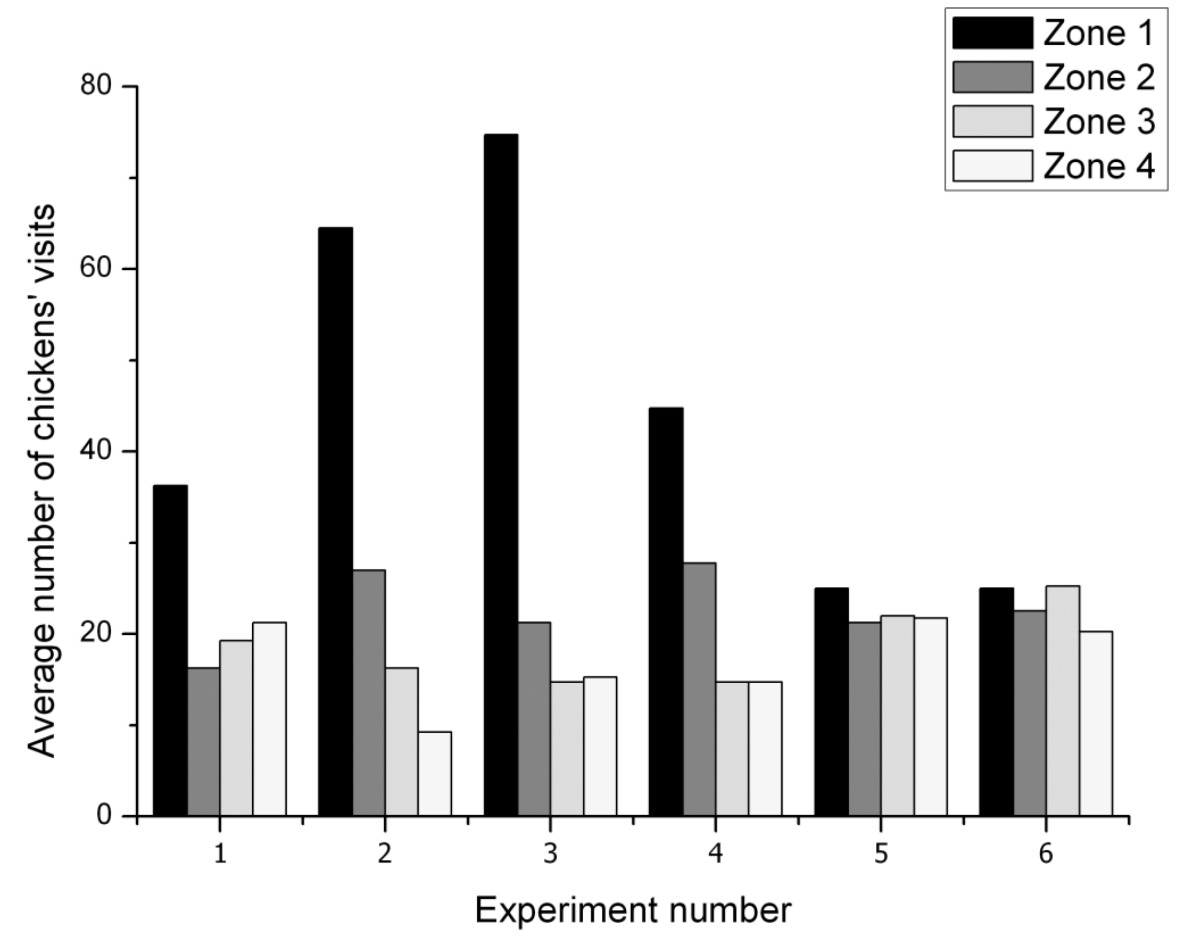

Fig. 5. The average number of chickens' visits to zones 1-4 for each experiment. 
Significant difference in number of chickens' visits between the zone 1 and the rest of the zones is shown in the table 2 .

Table 2. $P$ values obtained with independent t-test to test the hypothesis that the zones around the walls opposite to the entrance were.

\begin{tabular}{cc}
\hline Comparison between zones & P value \\
\hline Zone 1 vs Zone 2 & $0.026^{*}$ \\
Zone 1 vs Zone 3 & $0.010^{*}$ \\
Zone 1 vs Zone 4 & $0.009^{*}$ \\
\hline
\end{tabular}

* significant difference $(\mathrm{p}<0.05)$

\section{DISCUSSION}

It was shown that the chickens in the semi-commercialised broiler houses were not decreasing their activity during the whole growth period. Travelled distances of the chickens in total were not reduced in the 3 last weeks of their growth period ( $p>0.05$ in $89 \%$ of the observed sample). This was in agreement with the results found by [1] for broiler breeders during a 10 days observation period from week 25 to week 31. The same tendency was observed in our study but for broiler chickens during 42 days of growth.

There was no statistical difference in the activity of observed chickens between first and the last 3 weeks of their growth period. They [14] have suggested similar results, even though they have conducted experiments on the older chickens for a shorter period (day 27-42). On the other hand, our findings are not consistent with the conclusions of [15] who have claimed a pronounced drop in walking distances in the third week of age in the commercial fast growing birds.

Furthermore, we have investigated chickens' spatial preferences in the compartment. From figure 4 it can be concluded that chickens only preferred to be next to the wall opposite to the entrance. Considering division of surface of the house into four zones [Fig. 2], it could be observed from figure 5 that chickens preferred the zone 1 which is area around the wall farthest from the entrance. Significant difference in number of chickens' visits between the zone 1 and the rest of the zones is shown in the table 2. It can be noticed that there is a decrease, in number of visits between zone 1 and the rest of the zones [Fig. 5]. More specifically, it can be observed from table 1 and figure 5 that there was significant decrease in activity in five out of 12 observed chickens during experiment 5. Experiment 5 was performed from June until middle of July, where temperature in broiler house went up to $29^{\circ} \mathrm{C}$ in the last 3 weeks of the chickens' growth period. Higher temperatures might be an explanation for the significant decrease in activity in $42 \%$ of the observed birds during the experiment 5. No influences of the placement of the feeder were observed, opposite to the results of [2] in the case of high stocking densities ( 15 birds $\left./ \mathrm{m}^{2}\right)$. In our study, the observed birds did not restrict themselves around the feeders and the drinkers but used the whole surface area that was available. In agreement with [2] but contrary to [14] chickens searched for areas with the least disturbances, which in our experimental setup corresponded to the regions next to the walls farthest from the entrance.

\section{CONCLUSION}

To author knowledge this is the first study to follow the broiler chickens in semi-commercialized farm for the whole growth period of 42 days. The $89 \%$ of observed chickens did not show significant difference in activity between the first and the last 3 weeks. In addition, chickens showed preference to visit the zones around the wall farthest from the entrance and disturbance. 
The results of the study could be useful when assessing commercial broiler houses from an animal welfare point of view. Reported mobility of chickens is important for their survival and has therefore considerable impact on animal welfare as well as on efficient production on farms. Further research can be done with a wider sample of birds and higher sample rates for observation of individual locomotion behaviour. Some observations with higher sample rates were already carried out by using computerized video acquisition systems [4]. However, those studies were restricted to specific times during the day and shorter periods than the whole growth period of 42 days. The more systematic approach could be achieved in the future by introducing automatic continuous video acquisition systems to monitor the activity of individual birds in big commercial flocks during the whole growth period.

\section{REFERENCES}

[1] M.C. Appleby, S.N. Maguire, H.E. Mcrae, Movement by domestic-fowl in commercial flocks, Poultry Science, 64 (1985) 48-50.

[2] U. Arnould, J.M. Faure, Use of pen space and activity of broiler chickens reared at two different densities, Applied Animal Behaviour Science, 84 (2003) 281-296.

[3] W. Bessei, The behavior of broilers under intensive management conditions, Arch. Geflugelkd, 56 (1992) 1 - 7.

[4] D. Bizeray, I. Estevez, C. Letterrier, J.M. Faure, Effects of increasing environmental complexity on the physical activity of broiler chickens, Applied Animal Behaviour Science, 79 (2002) 27-41.

[5] H.J. Blokhuis, J.W. Van Der Haar, J.M.M. Fuchs, Do weighing figures represent the flock average? Poultry International, 4 (1988) 17 - 19.

[6] A. Chedad, J.M. Aerts, E. Vranken, M. Lippens, J. Zoons, D. Berckmans, Do heavy broiler chickens visit automatic weighing systems less than lighter birds? British Poultry Science, 44 (2003) 663-668.

[7] I. Doyle, S. Leeson, Automatic weighing of poultry reared on a litter floor, Can. J Animal Science, 69 (1989) 1075 - 1081.

[8] S.C. Kestin, S. Gordon, G. Su, P. Sorensen, Relationships in broiler chickens between lameness, live weight, growth rate and age, Vet. Rec., 148 (2001) 195 - 197.

[9] H. Kristensen, J.M. Aerts, T. Leroy, C.M. Wathes, D. Berckmans, Modelling the dynamic activity of broiler chickens in response to step-wise changes in light intensity, Applied Animal Behaviour Science, 101 (2006) 125-143.

[10] E.H. Leone, I. Estevez, Use of space in the domestic fowl, separating the effects of enclosure size, group size and density, Animal Behaviour, 76 (2008) 1673-1682.

[11] G. McBride, F. Foenander, Territorial behaviour in flocks of domestic fowls, Nature, 192 (1962) 102-106.

[12] R.C. Newberry, Exploratory behaviour of young domestic fowl, Applied Animal Behaviour Science, 63 (1999) 311-321.

[13] R. Pettit-Riley, I. Estevez, Effects of density on perching behaviour of broiler chickens, Applied Animal Behaviour Science, 71 (2001) 127 - 140.

[14] A.P. Preston, L.B. Murphy, Movement of broiler-chickens reared in commercial conditions, British Poultry Science, 30 (1989) 519-532.

[15] K. Reiter, W. Bessei, Effect of locomotor activity on bone development and leg disorders in broilers, Arch. Geflugelkd. 62 (1998) 247- 253. 
[16] P. Sørensen, G. Su, S.C. Kestin, Effects of age and stocking density on leg weakness in broiler chickens, Poultry Science, 79 (2000) 864 - 870.

[17] A.M. Eddie, P. Bokkers, H. Zimmerman, T. B. Rodenburg, P. Koene, Walking behaviour of heavy and light broilers in an operant runway test with varying durations of feed deprivation and feed access, Applied Animal Behaviour Science, 108 (2006) 1-2.

[18] M.S. Baracho, I.A. Nääs, L.G.F. Bueno, G.R. Nascimento, D.J. Moura, Broiler walking ability and toe asymmetry under harsh rearing conditions. Revista Brasileira de Ciência Avícola, 14 (2012) 217-222.

[19] S. Sultana, M.D. Hassan, C. Rakibul, R. Ho Sung, S. Kyeong, The effect of monochromatic and mixed LED light colour on the behaviour and fear responses of broiler chicken. Avian Biology Research, 6 (2013) 207-214.

[20] W. Bessei, Welfare of broilers: a review. World's Poultry Science Journal, 62 (2006) 455-456.

[21] R.A. Renema, M.E. Rustad, F.E. Robinson, Implications of changes to commercial broiler and broiler breeder body weight targets over the last 30 years. World's Poultry Science Journal, 63 (2007) 457-472.

[22] T.G. Knowles, S.C. Kestin, S.M. Haslam, S.N. Brown, L.E. Green, A. Butterworth, S.J. Pope, D. Pfeiffer, C.J. Nicol, Leg disorders in broiler chickens: prevalence, risk factors and prevention. PLoS One, 3 (2008) 38-45. 